\title{
Analysis of Volatile Compounds of Jasminum nitidum [Acc.JN.1] Flowers
}

\author{
P. Ranchana*, M. Ganga, M. Jawaharlal and M. Kannan \\ Department of Floriculture and Landscaping, HC\& RI, TNAU, \\ Coimbatore- 3, Tamil Nadu, India \\ *Corresponding author
}

\section{A B S T R A C T}

Keywords

Jasmine- Jasminum nitidum-concretevolatile compoundsGC-MS

Article Info

Accepted:

31 October 2017

Available Online:

10 November 2017
Essential oil or also known as ethreal oil is a concentrated, hydrophobic liquid that contains hundreds of aromatic compounds, organic constituents, including hormones, vitamins and other natural elements. Jasmine essential oil has a sweet and floral aroma that aids the body as anti-depressant and aphrodisiac properties. India is one of the centres of origin of jasmine. The genus Jasminum is reported to comprise of 500 species (Bailey, 1958). The chemical composition of the Jasminum nitidum [Acc.JN.1] concrete was analysed by gas chromatographymass spectrometry (GC-MS). The major chemical components detected are 1Pentanol, 4-methyl-2-propyl; Pentane, 3-ethyl-2,2-dimethyl-; Pentane, 2,2,3,4tetramethyl. The result of this study showed that the GC-MS study is selective, rapid and efficient for the identification of volatile components and composition variations.

\section{Introduction}

Jasmine is one of the most popular and important traditional loose flowers grown in India. Three species of jasmine viz., Jasminum sambac, Jasminum auriculatum and Jasminum grandiflorum are cultivated in a commercial scale (Rimando, 2003; Green and Miller, 2009). It holds a vital place in all the religious, social and cultural activities of the Indian society. Jasmine flowers have multifarious uses including use as fresh flowers for garland making for adorning hair of women and in religious offerings and also for extraction of its highly valued essential oil which is popularly used in the perfumery industry. Tamil Nadu Agricultural University, Coimbatore has identified a new clone in $J$. nitidum as Acc.JN-1. The flower buds possess dark pink colour, whereas the open flowers are white in colour and shows resistant to pests and diseases. It also possesses long corolla tube length which favours easy string making. The fully blossomed flower is used to extract its oil and concrete

Concrete is extracted from the freshly harvested flower or when the fragrance emission is slow. A non-polar solvent such as Hexane is used to "wash" the aromatic compounds out of the flowers. After the hexane is evaporated a waxy, semisolid substance known as a "concrete" is left. The concrete then undergoes a series of "washings" with a polar solvent such as ethanol. The polarity of the ethanol will allow 
extraction of the volatile aromatics from the concrete while leaving behind the non-polar plant waxes which do not dissolved in the ethanol. Finally, the ethanol is evaporated to leave behind the ABSOLUTE which will typically have $1-5 \%$ ethanol remaining in it and sometimes a trace of hexane. The volatile emission pattern varies widely in different climatic conditions and between different genotypes.

Gas Chromatography-Mass Spectrometry (GCMS) is a process that integrated the features of gas chromatography and mass spectrometry to improve efficacy of qualitative and quantitative analysis within a test sample. The gas chromatograph applies which depend on the column (type, material, length, diameter, film thickness) as well as the phase properties. The mass spectrometer does this by breaking each molecule into ionized fragments and detecting these fragments using their mass to charge ratio (Bramer, 1998). Applications of GC-MS include drug detection, plasma detection, fire investigation, environmental analysis, explosives investigation, and identification of unknown samples. Additionally, it can identify trace elements in materials that were previously thought to have disintegrated beyond identification. The purpose of this study was to identify the volatile compounds released from Jasminum nitidum [Acc.JN.1].

\section{Materials and Methods}

\section{Flower preparations}

Freshly opened blossoms were collected every day before 9.30 a.m., weighed and subjected to extraction.

\section{Extraction method- Solvent extraction}

For extraction of concrete, the flowers were harvested when fully opened before 9.30 AM.
Concrete content of flowers was analyzed by solvent extraction method (ASTA, 1960) with food grade hexane, averaged and expressed in per cent of concrete recovery.

A sample of fifty gram was taken in the glass column of Soxhlet appraratus and concrete content was estimated using food grade hexane as solvent. Soluble extract was then drained off into a pre weighed $100 \mathrm{ml}$ beaker $\left(\mathrm{W}_{1}\right)$. The extract was then evaporated on a steam bath and heated for 30 minutes in an oven at $60^{\circ} \mathrm{C}$, cooled and weighed $\left(\mathrm{W}_{2}\right)$. The concrete content was calculated using the following formula and expressed in per cent.

Concrete content $(\%)=\frac{\mathrm{W}_{2}-\mathrm{W}_{1}}{---------\mathrm{X}} 100$

\section{Volatile compound analysis using GC/MS analysis}

The volatile oil from jasmine flowers was dissolved in hexane and directly injected into the injection port of gas chromatograph (Agilent Technologies 7890A GC system) coupled with a mass spectrometer (Agilent Technologies 5975C inert XL EI/CI MSD with Triple-Axis Detector).

The GC was operated on an Agilent J\&W GC column HP5 column (30 m x $0.32 \mathrm{~mm}$, id. with $0.52 \mu \mathrm{m}$ film thickness) and helium was used as the carrier gas.

The temperature program was started with an initial temperature of $150^{\circ} \mathrm{C}$ and held for 4 min at this temperature, then heated up to $170^{\circ} \mathrm{C}$ with a heating rate of $0.8^{\circ} \mathrm{C} / \mathrm{min}$ and held for $1 \mathrm{~min}$, heated up to $220^{\circ} \mathrm{C}$ with a heating rate of $3.0^{\circ} \mathrm{C} / \mathrm{min}$ and held for $1 \mathrm{~min}$, heated up to $240^{\circ} \mathrm{C}$ with a heating rate of $1.0^{\circ} \mathrm{C} / \mathrm{min}$ and held for $1 \mathrm{~min}$ and heated up to $250^{\circ} \mathrm{C}$ with a heating rate of $5.0^{\circ} \mathrm{C} / \mathrm{min}$ and held for $5 \mathrm{~min}$ at a flow rate of $0.7 \mathrm{~mL} / \mathrm{min}$. 
Table.1 Chemical composition of Jasminum nitidum

\begin{tabular}{|c|c|c|c|c|}
\hline S.No & RT & Compounds available & $\begin{array}{l}\text { Molecular } \\
\text { weight }\end{array}$ & $\begin{array}{c}\% \text { Retention } \\
\text { area }\end{array}$ \\
\hline 1. & 2.10 & 1-Pentanol, 4-methyl-2-propyl & 144 & 50.30 \\
\hline 2. & 2.10 & Pentane, 3-ethyl-2,2-dimethyl- & 128 & 50.30 \\
\hline 3. & 2.10 & Pentane, 2,2,3,4-tetramethyl- & 128 & 50.30 \\
\hline 4. & 2.10 & 1-Hexene, 3,4-dimethyl- & 112 & 50.30 \\
\hline 5. & 2.10 & 1-Heptene, 2,6,6-trimethyl- & 140 & 50.30 \\
\hline 6. & 29.07 & Diisooctyl phthalate & 390 & 14.67 \\
\hline 7. & 29.07 & Bis(2-ethylhexyl) phthalate & 390 & 14.67 \\
\hline 8. & 29.07 & $\begin{array}{lll}\text { Phthalic } & \text { acid, } & \operatorname{di}(2- \\
\text { propylpentyl) ester }\end{array}$ & 390 & 14.67 \\
\hline 9. & 29.07 & $\begin{array}{l}\text { Phthalic acid, di(6-methylhept- } \\
\text { 2-yl) ester }\end{array}$ & 390 & 14.67 \\
\hline 10. & 29.07 & $\begin{array}{l}\text { Phthalic acid, 6-ethyloct-3-yl 2- } \\
\text { ethylhexyl ester }\end{array}$ & 418 & 14.67 \\
\hline
\end{tabular}


Fig.1 The GC chromatogram of volatile compounds of Jasminum nitidum [Acc.JN.1]

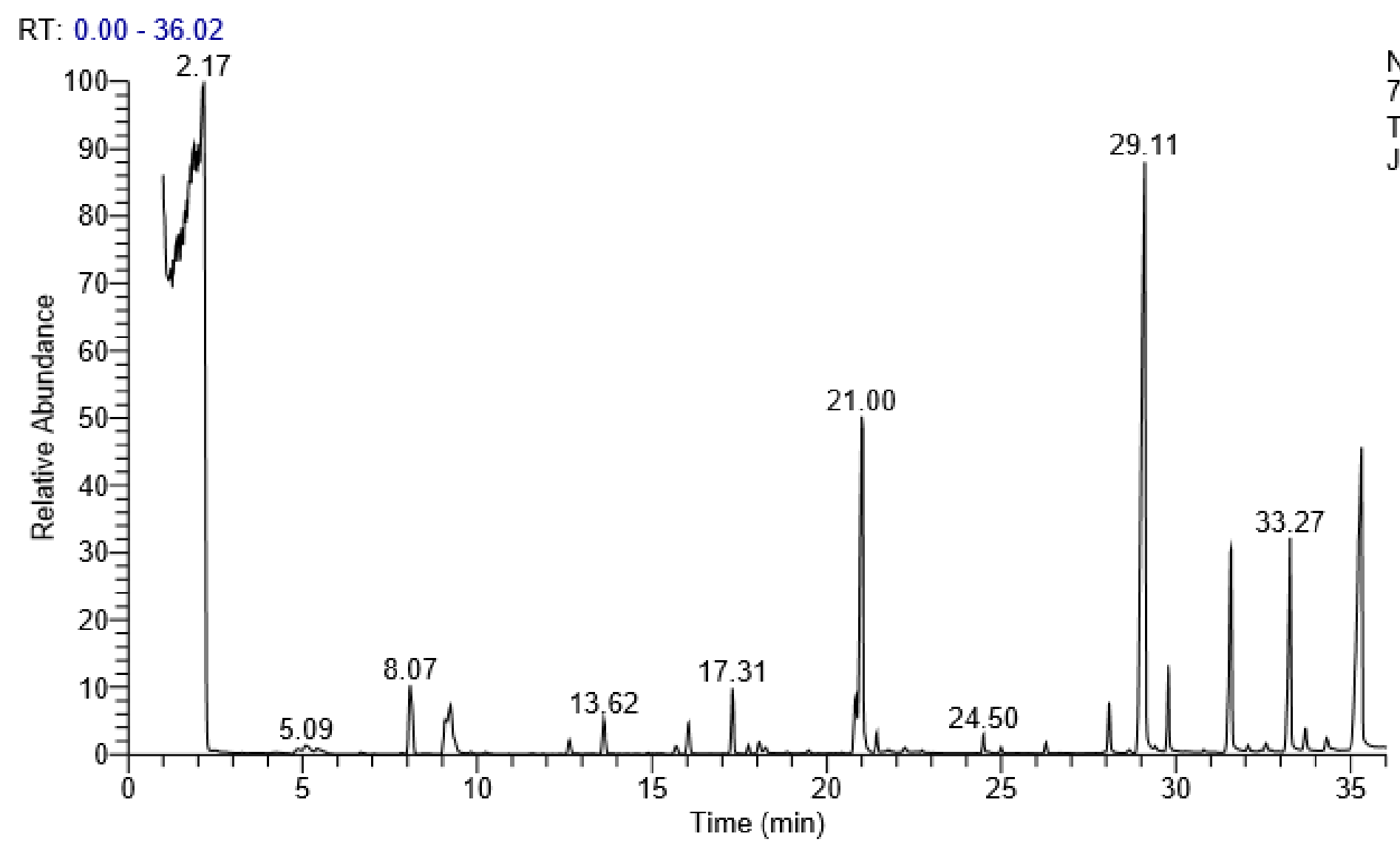

$\mathrm{NL}:$ 7.82E8

TIC MS Jnitidum 
Fig.2 Chemical structure of volatile compounds of Jasminum nitidum [Acc.JN.1]
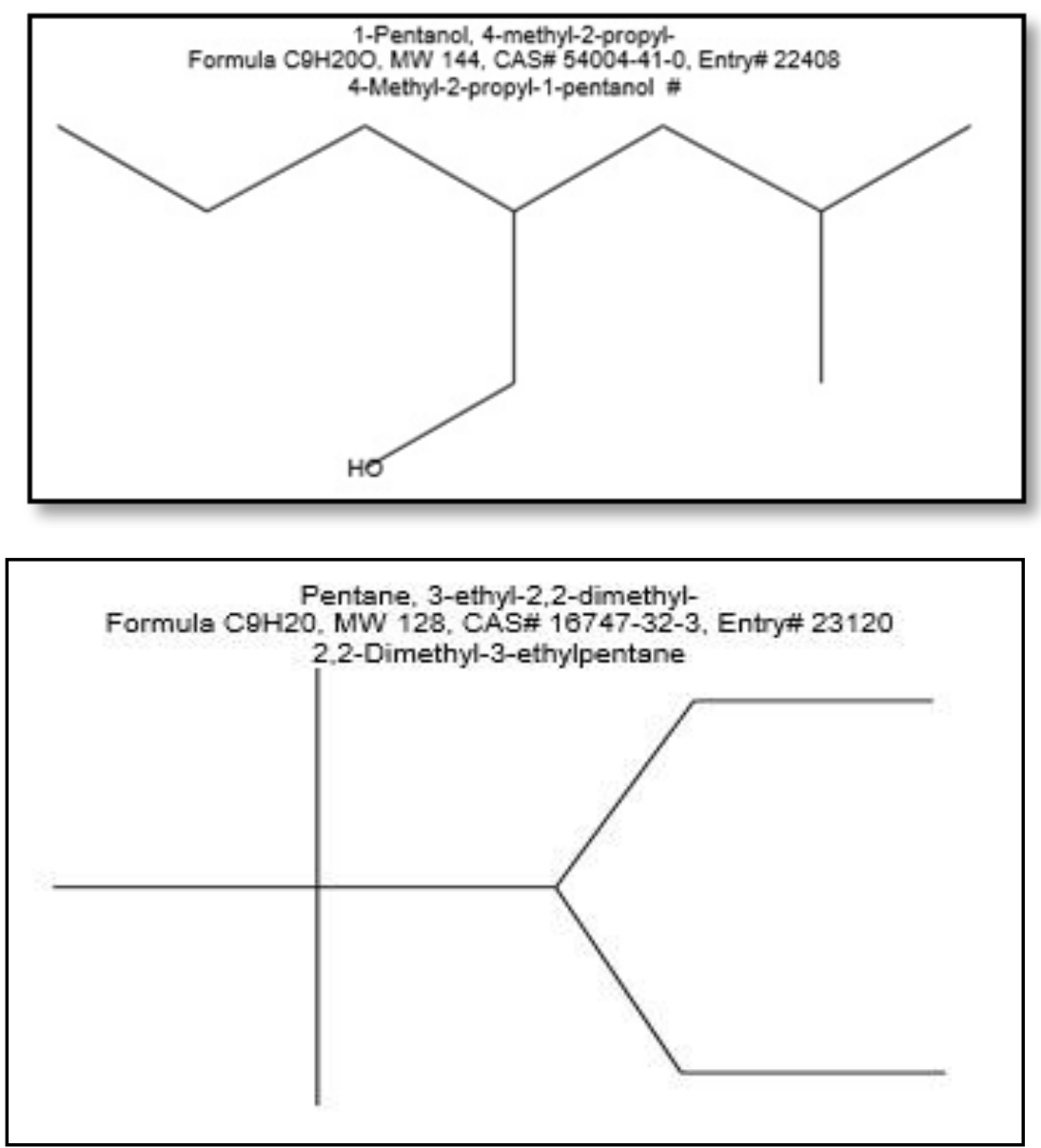

Pentane, 2,2,3,4-tetramethyl-

Formula C8H20, MW 128, CAS\#1186-53-4, Entry\# 22488

2,2,3,4-Tetramethylpentane

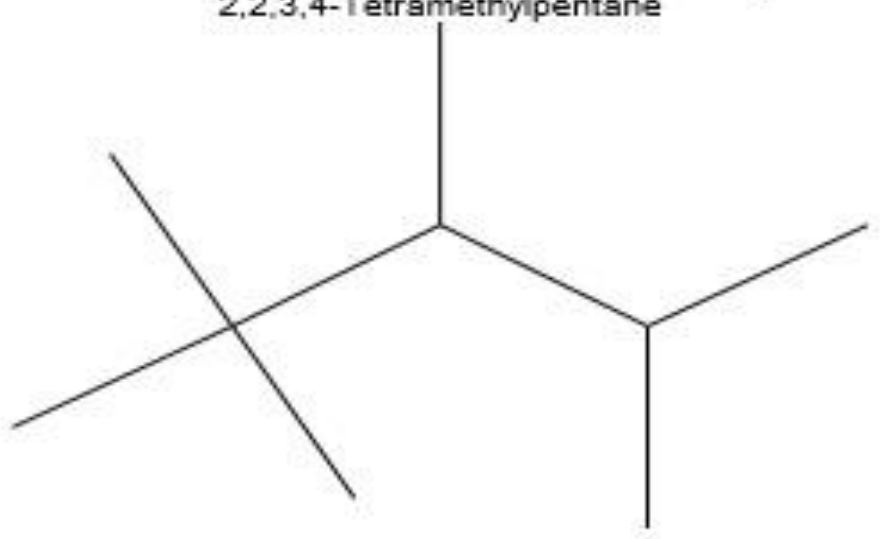



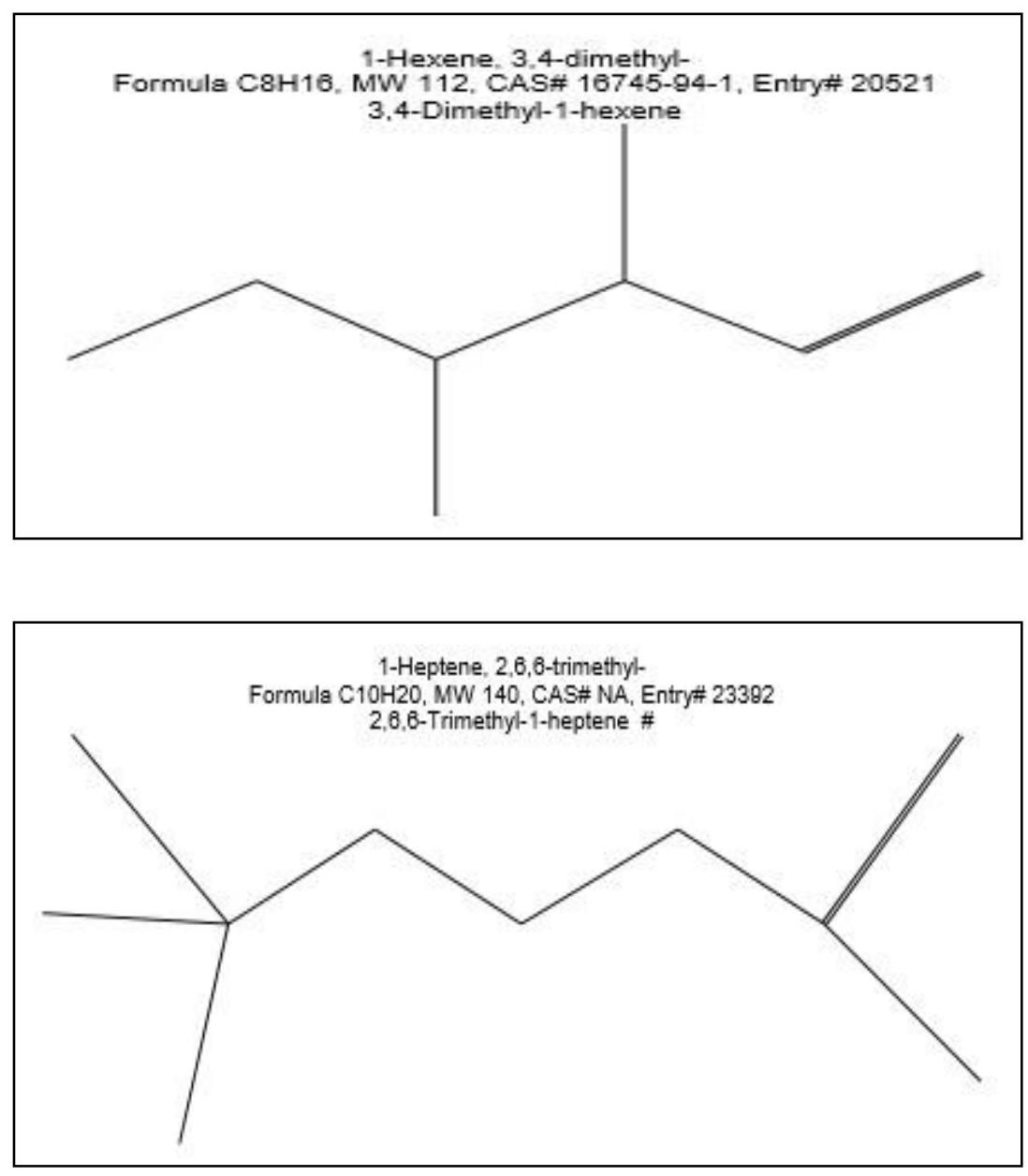

\section{Diisooctyl phthalate}

Formula C24H3804, MW 390. CAS\# 131-20-4, Entry\# 122868 Bis(6-methylhepty) phthalate<smiles>CC(C)CCCCCCOC(=O)c1ccccc1C(=O)OCCCCCC(C)C</smiles> 
Int.J.Curr.Microbiol.App.Sci (2017) 6(11): 5411-5418
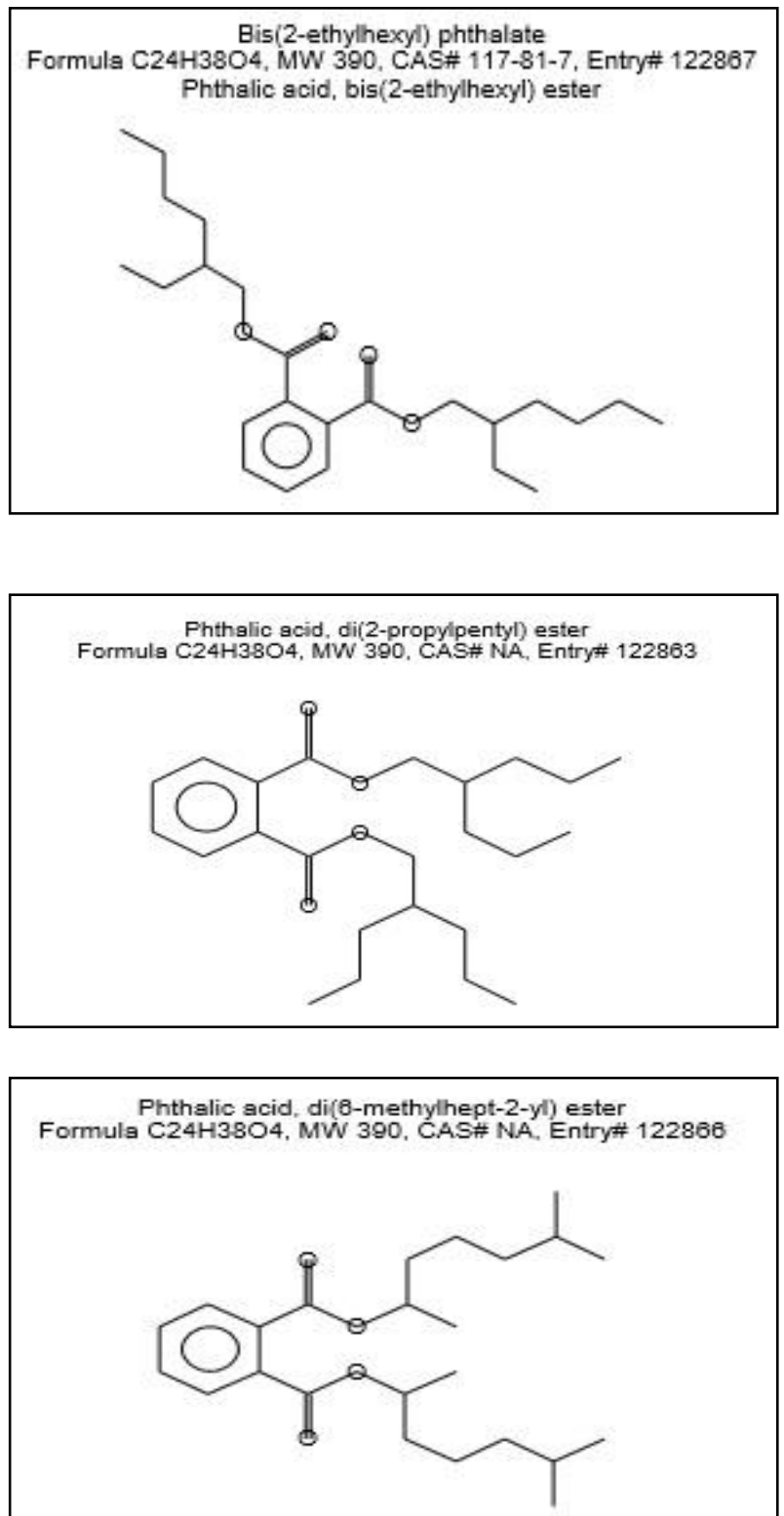

Phthalic acid, 6-ethyloct-3-yl 2-ethylhexyl ester Formula C28H42O4, MW 418, CAS\# NA, Entry\# 122963

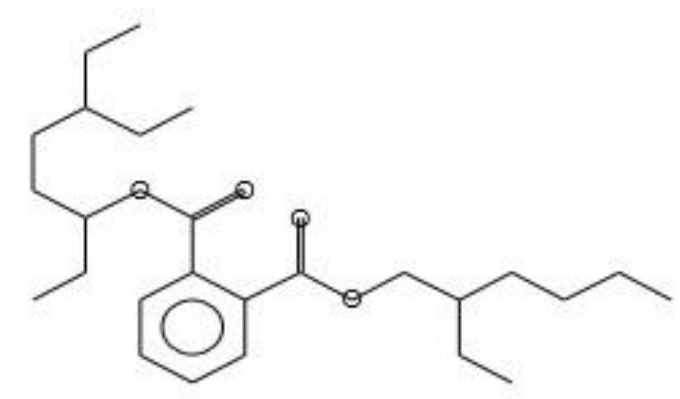


The obtained mass spectra were preliminarily interpreted by comparing with those of Enhance Chemstation Version D00.00.38 (Agilent Technologies), the Mass Spectral Search Library of the National Institute of Standards and Technology (NIST, Gaithersburg, USA).

\section{Results and Discussion}

The concrete of Jasminum nitidum clone Acc.JN.1 was prepared by solvent extraction and it constitutes $0.32 \%$ cent. The chromatogram generated by gas chromatography showed that the composition of the volatile oils from Jasminum nitidum clone Acc.JN.1 (Fig.1).

GC/MS analysis of Jasminum nitidum concrete resulted in the identification of major compounds as 1-Pentanol, 4-methyl-2-propyl; Pentane, 3-ethyl-2,2-dimethyl-; Pentane, 2,2,3,4-tetramethyl-; 1-Hexene, 3,4-dimethyl; 1-Heptene, 2,6,6-trimethyl-; Diisooctyl phthalate; Bis (2-ethylhexyl) phthalate; Phthalic acid, di(2-propylpentyl) ester; Phthalic acid, di (6-methylhept-2-yl) ester and Phthalic acid, 6-ethyloct-3-yl 2-ethylhexyl ester (Table 1, Fig 2). Whereas, 1-
Heptatriacotanol; 2,5-Octadecadiynoic acid, methyl ester; 7-epi-cis-sesquisabinene hydrate; 7-epi-trans-sesquisabinene hydrate and 2H-Pyran, 2-(7-heptadecynyloxy) tetrahydro- were present as minor compounds.

\section{References}

1. ASTA 1960. Official analytical methods of the American Spice Trade Association, New York, pp. 41-42.

2. Bailey, L. H. 1958. Manual of cultivated plants. Macmillan and Co. New York.

3. Bramer S. E. V.1998. An Introduction to Mass Spectrometry. Widener University. Department of Chemistry. pp.26.

4. Green, P. and Miller, D. 2009. The genus Jasminum in cultivation. Kew Publishing, Royal Botanic Gardens, Kew.

5. Rimando, T. J. 2003. Sampaguita production. In: Ornamental Horticulture: A little giant in the tropics. SEAMEO SEARCA and UPLB, College, Los Banos, Laguna, Philippines, pp: 333.

\section{How to cite this article:}

Ranchana P., M. Ganga, M. Jawaharlal and Kannan M. 2017. Analysis of Volatile Compounds of Jasminum nitidum [Acc.JN.1] Flowers. Int.J.Curr.Microbiol.App.Sci. 6(11): 5411-5418. doi: https://doi.org/10.20546/ijcmas.2017.611.517 